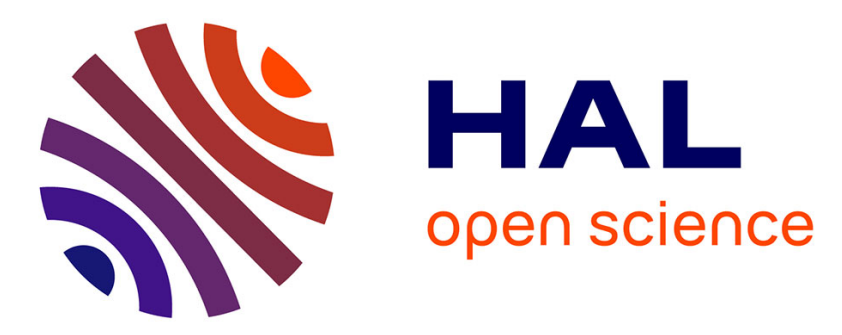

\title{
A two-step chemical scheme for kerosene-air premixed flames
}

B. Franzelli, E. Riber, M. Sanjosé, Thierry Poinsot

\section{To cite this version:}

B. Franzelli, E. Riber, M. Sanjosé, Thierry Poinsot. A two-step chemical scheme for kerosene-air premixed flames. Combustion and Flame, 2010, 157 (7), pp.1364-1373. 10.1016/j.combustflame.2010.03.014 . hal-01272968

\section{HAL Id: hal-01272968 https://hal.science/hal-01272968}

Submitted on $20 \mathrm{Jul} 2017$

HAL is a multi-disciplinary open access archive for the deposit and dissemination of scientific research documents, whether they are published or not. The documents may come from teaching and research institutions in France or abroad, or from public or private research centers.
L'archive ouverte pluridisciplinaire HAL, est destinée au dépôt et à la diffusion de documents scientifiques de niveau recherche, publiés ou non, émanant des établissements d'enseignement et de recherche français ou étrangers, des laboratoires publics ou privés. 


\title{
A two-step chemical scheme for kerosene-air
}

\section{premixed flames}

\author{
B. Franzelli ${ }^{a}, *$, E. Riber ${ }^{a}$, M. Sanjosé ${ }^{a}$ and T. Poinsot ${ }^{b}$ \\ ${ }^{a}$ CERFACS, CFD Team, 42 Avenue G. Coriolis, 31057 Toulouse Cedex 01, France \\ ${ }^{\mathrm{b}}$ IMFT-UMR 5502, allée du Professeur Camille Soula, 31400 Toulouse, France
}

\begin{abstract}
A reduced two-step scheme (called 2S_KERO_BFER) for kerosene-air premixed flames is presented in the context of Large Eddy Simulation of reacting turbulent flows in industrial applications. The chemical mechanism is composed of two reactions corresponding to the fuel oxidation into $\mathrm{CO}$ and $\mathrm{H}_{2} \mathrm{O}$, and the $\mathrm{CO}-\mathrm{CO}_{2}$ equilibrium. To ensure the validity of the scheme for rich combustion, the preexponential constants of the two reactions are tabulated versus the local equivalence ratio. The fuel and oxidizer exponents are chosen to guarantee the correct dependence of laminar flame speed with pressure. Due to a lack of experimental results, the detailed mechanism of Dagaut composed of 209 species and 1673 reactions, and the skeletal mechanism of Luche composed of 91 species and 991 reactions have been used to validate the reduced scheme. Computations of onedimensional laminar flames have been performed with the 2S_KERO_BFER scheme using the CANTERA and COSILAB softwares for a wide range of pressure $([1 ; 12]$ atm), fresh gas temperature ([300;700] K), and equivalence ratio ([0.6;2.0]). Results show that the flame speed is correctly predicted for the whole range of parameters, showing a maximum for stoichiometric flames, a decrease for rich combustion and a satisfactory pressure dependence. The burnt gas temperature and the dilution
\end{abstract}


by Exhaust Gas Recirculation are also well reproduced. Moreover, the results for ignition delay time are in good agreement with the experiments.

Key words: kerosene, reduced chemical scheme, pre-exponential factor tabulation, pressure and temperature dependence

* Corresponding author.

Address: CERFACS, CFD Team, 42 Avenue G. Coriolis, 31057 Toulouse Cedex 01, France.

Tel: +33 (0)5 611930 83; fax: +33 (0)5 61193000 .

Email address: franzell@cerfacs.fr (B. Franzelli). 


\section{Introduction}

The integration of detailed kinetics into turbulent flame simulations is one of the most difficult challenges in the combustion community. Multiple theories have been developed for specific turbulent combustion regimes where assumptions on the flame structure can be used (infinitely fast chemistry, flamelet assumptions for example [1,2]) but very few methods can provide information on flame - turbulence interaction in the general case. Among these methods, pdf approaches have demonstrated their potential [3] but their implementation requires specific developments to limit their cost. Most of these developments use assumptions on the trajectories in composition space such as Intrinsic Low-Dimension Manifold (ILDM) [4] and tabulation ideas such as In Situ Adaptive Tabulation (ISAT) [4-6].

Cost becomes a more difficult issue when such methods must be used in unsteady simulations such as Large Eddy Simulation (LES) where the conservation equations must be solved at each time step. For such flows, alternative techniques have been proposed based on Conditional Moment Closure (CMC) [7-10] or on tabulation methods coupled to assumptions on the flame structure such as Flame Generated Manifold (FGM) [11,12] or Flame Prolongation of ILDM (FPI) [13-17].

The power of all these methods is clearly demonstrated in validation exercises such as the test cases proposed in the Turbulent Non-premixed Flame (TNF) workshop (public.ca.sandia.gov/TNF) where detailed measurements are compared to LES and Reynolds-Averaged Navier-Stokes (RANS) sim- 
ulation data [18-23]. However, when it comes to industrial applications, a major issue associated to tabulation methods is their extension to cases where the number of parameters which must be taken into account increases drastically: for example, in a piston engine, tabulating chemistry requires to account for heat losses, fresh gas temperature and pressure, dilution by recirculating gases... In a gas turbine, the combustion may be fed by more than one stream (for example fuel, cold air and heated air), requiring more than one passive scalar to describe mixing. Generating and handling the lookup table can become difficult in such situations. First, the dimensions of the lookup table required for FGM or FPI in such situations grow very rapidly and can lead to memory problems on massively parallel machines where the table must be duplicated on each core. A solution is then to use self-similarities in the flame structure in order to reduce the table size and the memory resources [24-26]. Second, determining which prototype flame should be used for combustors where the combustion regime is unknown can be a complicated task: clearly, a tabulation based on zero-dimensional ignition (Perfectly Stirred Reactor (PSR) for example [27]) is adequate to compute a turbulent self-igniting flame such as the Cabra et al. experiment $[28,29]$. Similarly, a tabulation based on laminar diffusion flames is a good choice for many non-premixed burners. But if the turbulent burner has multiple inlets and can feature flame elements which are premixed or not, autoignite or not, choosing the right laminar configuration to tabulate chemistry becomes almost impossible.

Another solution is to come back to simpler alternative methods where a reduced chemical scheme is directly used in the LES instead of the tabulation of a complex scheme. The papers of Westbrook and Dryer [30] or Jones 
and Lindstedt [31] have shown long ago that one- to four-step chemical schemes have the capacities to reproduce multiple aspects of flames even though they obviously lack the precision of full schemes. Considering the limited precision associated inherently to flame-turbulence models, using reduced schemes in LES is an alternative solution which can be attractive in certain cases for the following reasons:

- In many industrial applications, only a few species are of interest and taking into account a large set of species is usually not needed. In gas turbines for example, being able to predict the chamber efficiency (which requires a correct prediction of fuel reaction rates), the outlet temperature (which requires correct equilibrium computations) as well as the $C O$ and NO composition is sufficient for a large part of the design process.

- Since cost in LES remains a main issue, using reduced schemes leads to solutions which are significantly cheaper in both CPU time and memory than tabulation methods.

- The coupling of reduced schemes with fully compressible codes is a straightforward task whereas it can be difficult in tabulation methods: this coupling must take place through the reaction rate terms and may lead to integration errors [32].

- With simple adjustments, reduced schemes can predict the evolution of flame quantities such as laminar flame speed, adiabatic flame temperature or ignition delay over a wide range of operating conditions (pressure, temperature, dilution) making their use in a LES code very easy.

- Reduced schemes can be used in conjunction with almost all flameturbulence interaction submodels. 
This explains why LES based on reduced schemes have been used successfully in complex burners [33-38] and may still offer a reasonable choice for many applications.

This paper concentrates on gas turbine combustion and describes a reduced two-step scheme for kerosene-air flames called 2S_KERO_BFER. The objective is to predict accurately laminar premixed flame speed, adiabatic flame temperature, $\mathrm{CO}$ levels at equilibrium and ignition delays for a wide range of equivalence ratio $([0.6 ; 2.0])$, fresh gas temperature $([300 ; 700] K)$, pressure $([1 ; 12] \mathrm{atm})$ and Exhaust Gas Recirculation (EGR) dilution ([0;10]\%) which covers almost completely the range required for many practical applications. As few experimental results are available, the reduced scheme is validated using both available measurements [39] and numerical simulations including one skeletal [40] and one detailed mechanism [41]. The flame data which are used for comparison are adiabatic flame temperature and laminar flame speeds [40] as well as ignition delay times [41-43].

To fit the parameters of the two-step scheme, the solution proposed in this work is a tabulation of the reaction constants as proposed by other authors $[36,44,45]$. In the present scheme, only the pre-exponential constants of the two reactions are adjusted and they are tabulated versus the local equivalence ratio. The implementation of such schemes in existing LES solvers is straightforward and costs little, allowing to add more grid points for the same CPU time. All calculations required first to adjust the rate constants, and then to validate the reduced two-step scheme are performed with the CANTERA software [46], except for the ignition delay calculation performed with the COSILAB software [47]. 


\section{Available data for kerosene}

To fit the constants of a reduced scheme, experimental and/or numerical results including full chemistry are needed for flame speeds, flame temperatures and ignition times.

\subsection{Experimental data for kerosene-air flames}

Multiple studies provide ignition times and laminar flame speeds for hydrogen [48-50] or simple fuels such as methane [51-53] over a wide range of pressure and temperature. For kerosene however, much less information is available. Regarding the ignition delay time, a very limited database was available until recently [54-56]. New experimental devices such as heated shock tubes operating at a wide range of temperature and pressure now complete the database [41-43]. One relevant result for ignition delay times $\tau$ is the following Arrhenius expression derived from the experiments:

$$
\tau=\tau_{0}\left(\frac{P}{P_{a t m}}\right)^{-0.39} \phi^{-0.57} e^{\left[\frac{T_{0}}{T}\right]}
$$

where $\tau_{0}=10^{-3} \mu s, T_{0}=14,700 \mathrm{~K}$ and $P_{a t m}$ is the atmospheric pressure. This expression correctly describes the experimental ignition delay for a wide range of initial temperature $(900 \mathrm{~K}<\mathrm{T}<1500 \mathrm{~K})$, pressure $(10 \mathrm{~atm}<P<$ $20 \mathrm{~atm})$ and equivalence ratio $(0.5<\phi<2.0)$ as shown in Fig. 1a. Moreover, Freeman and Lefebvre [56] showed that the ignition delay time of kerosene can be expressed in terms of mixture activation energy $E_{a}$ :

$$
\tau \propto \mathrm{e}^{\left[\frac{E_{a}^{e x p}}{R T}\right]}
$$


where $R$ is the universal gas constant and $E_{a}^{\exp }$ is the activation energy de-

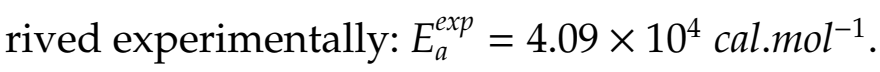

Very few experimental results on flame speeds are available. Recently, Eberius et al. [39] measured the burning velocity for kerosene, n-decane and a mixture of $80 \%$ n-decane/20\% n-propylbenzene in weight as fuel, but only at atmospheric pressure and fresh gas temperature $T_{f}=473 \mathrm{~K}$ (where the subscript $f$ denotes fresh gases), as reproduced in Fig. 1b.These experimental results exhibit a variability close to $10 \%$ for kerosene in the lean regime which increases up to $30 \%$ in the rich regime. This large variability of flame speed results and the fact that the experimental data were available only at atmospheric pressure and fresh gas temperature $T_{f}=473 \mathrm{~K}$ shows that available experiments are not sufficient to build a reduced two-step scheme. Consequently, numerical simulations using detailed and skeletal chemical kinetic mechanisms for kerosene-air flames (see Section 2.1) will be used to validate the 2 S_KERO_BFER scheme.

\subsection{Kerosene chemical kinetic models}

To fit the coefficients of the two-step scheme developed in this paper, reference values for flame speeds, adiabatic temperatures and ignition delays were needed. They were obtained using zero-dimensional and onedimensional numerical simulations including complex chemistry. This section presents the three mechanisms (two detailed mechanisms $[41,57]$ and one skeletal mechanism [40]) used for these simulations. 
Several detailed chemical kinetic mechanisms have been developed for kerosene-air flames, as described in [41]. Among them, some aim at correctly reproducing some fundamental flame characteristics and combustion phenomena such as species profiles or ignition delay. Unfortunately, none of them has been validated against laminar flame speed.

To validate the 2S_KERO_BFER scheme, two detailed mechanisms and one skeletal mechanism have been chosen, all using the same description for the fuel which is mainly composed of n-decane $\left(\mathrm{C}_{10} \mathrm{H}_{22}\right)$, and also contains some aromatic $\left(\mathrm{C}_{9} \mathrm{H}_{12}\right)$ and naphthenic $\left(\mathrm{C}_{9} \mathrm{H}_{18}\right)$ components, the exact composition being detailed in Table 1:

- The DAGAUT detailed mechanism [41] is composed of 209 species and 1673 reversible reactions. It correctly predicts the ignition delay (tested for equivalence ratio $\phi=0.5$ and pressure $P=1$ to $20 \mathrm{~atm}$ ), the kerosene oxidation in a jet-stirred reactor (JSR) (tested for $P=1,10,40 \mathrm{~atm}$ ) and the flame structure (tested for $P=a t m$ and $\phi=1.7)$.

- The EL-BAKALI_RISTORI detailed mechanism [57] is composed of 225 species and 1800 reversible reactions. It has been validated in a perfectlystirred reactor (PSR) in the ranges of temperature $T=300-1800 \mathrm{~K}$, pressure $P=0.5-10 \mathrm{bar}$, and equivalence ratio $\phi=0.5-2.0$.

- The LUCHE skeletal mechanism [40] derives from the EL-BAKALI_RISTORI detailed mechanism. It accounts for 91 species and 991 reactions and has been validated doing the same PSR calculations as for the EL-BAKALI_RISTORI detailed scheme.

Being interested in the laminar flame speed description, premixed flame calculations have been performed with the three detailed or skeletal chemi- 
cal kinetic schemes for equivalence ratio $\phi=0.8-1.5$, fresh gas temperature $T_{f}=473 \mathrm{~K}$, and atmospheric pressure. A comparison with the experimental results from Eberius et al. [39] is proposed in Fig. 2. The flame speed evolution is similar for the three mechanisms, but a non-negligible translation in the y-direction is observed. The discrepancies between the two detailed mechanisms are reasonable. Moreover, Lu \& Law [58] have shown that a skeletal mechanism can predict a larger flame speed than its parent detailed mechanism, which justifies the differences between the LUCHE skeletal scheme and the EL-BAKALI_RISTORI detailed mechanism. For lean or stoichiometric mixtures, all three mechanisms underestimate the measurements of Eberius et al [39], with a maximum error at $\phi=0.9$ of 15\% using the LUCHE skeletal mechanism and 25\% with the DAGAUT detailed mechanism. For rich flames, the laminar flame speed is correctly predicted by the DAGAUT detailed scheme, and overestimated of 35\% by the LUCHE skeletal mechanism. The EL-BAKALI_RISTORI results vary between the two other mechanisms for the whole range of equivalence ratios. Figure 2 obviously shows that there are large flame speed variations between all numerical simulations and experiments, raising the question of which one of these sets of data should be used to calibrate the 2S_KERO_BFER scheme. It was decided here to fit the two-step scheme using the LUCHE skeletal mechanism because it is closer to experimental data in the lean regime. In flame speed figures displayed in Section 4, the results of the DAGAUT detailed mechanism will be added for comparison to provide an estimate of the uncertainty on flame speed data at various pressures and fresh gas temperatures. 
One objective of this work is to construct a semi-global scheme valid for a wide range of pressure and temperature. Flame speeds are known to increase rapidly when the temperature of the fresh gases increases, and to decrease when pressure increases. Experimental results [53,59] show that the dependence of laminar flame speed $s_{L}$ with pressure $P$ or temperature $T$ can be approximated by:

$$
s_{L}(P, T)=s_{L}\left(P_{0}, T_{0}\right)\left(\frac{P}{P_{0}}\right)^{\alpha_{P}}\left(\frac{T}{T_{0}}\right)^{\alpha_{T}}
$$

where $P_{0}$ and $T_{0}$ are the reference temperature and pressure, and $\alpha_{P}$ and $\alpha_{T}$ are respectively the pressure and temperature exponents.

Both the DAGAUT detailed and the LUCHE skeletal mechanisms have been analysed in terms of pressure and temperature dependence to validate the simplified mechanism on a wide range of pressure and temperature. Table 3 provides values for the pressure exponent computed from the detailed LUCHE skeletal and DAGAUT detailed mechanisms for three equivalence ratios $(0.8,1.0,1.2)$ at fresh gas temperature $T_{f}=300 \mathrm{~K}$. The pressure exponent is measured in CANTERA running the code from $P=1 \mathrm{~atm}$ to $P=12 \mathrm{~atm}$. Despite the discrepancies in flame speed displayed in Fig. 2, the pressure exponent $\alpha_{P}$ is almost constant, showing that the response to pressure is similar for both mechanisms. The mean value for the pressure exponent is $\bar{\alpha}_{P}=-0.275$. As an example, Fig. 3a. shows that Eq. (3) fits the LUCHE skeletal mechanism results quite well at temperature $T_{f}=300 \mathrm{~K}$, once $\bar{\alpha}_{P}=-0.275$ has been chosen for the pressure exponent with $T_{0}=300 \mathrm{~K}$ and $P_{0}=1 \mathrm{~atm}$ in Eq. (3). 
For a one-step scheme and lean combustion, the pressure exponent $\alpha_{P}$ is roughly linked to the fuel and oxidizer reaction exponents, respectively $n_{F}$ and $n_{O}[2]$ :

$$
\alpha_{P}=\frac{n_{F}+n_{O}-2}{2}
$$

Equation (4) and the fact that $\alpha_{P}$ remains close to $\bar{\alpha}_{P}=-0.275$ over a wide range of equivalence ratio and pressure will also be exploited in Section 3 to choose the fuel and oxidizer exponents $n_{F}$ and $n_{O}$ so that the pressure dependence of the two-step scheme also remains close to $\bar{\alpha}_{P}=-0.275^{1}$.

It is more difficult to anticipate a link between the temperature exponent $\alpha_{T}$ and the reaction parameters, and theoretical evaluations of $\alpha_{T}$ for single-step schemes are usually inaccurate [2]. Table 3 gives values for the temperature exponent computed from the LUCHE skeletal and DAGAUT detailed mechanisms for three equivalence ratios at pressure $P=1 \mathrm{~atm}$. The temperature exponent is almost constant, with a mean value $\bar{\alpha}_{T}=1.9$, showing again that the response to a temperature variation is similar for both mechanisms. As an example, Fig. 3b. shows that Eq. (3) fits the Luche skeletal mechanism results quite well at $P=1 \mathrm{~atm}$ using $\bar{\alpha}_{T}=1.9, T_{0}=300 \mathrm{~K}$ and $P_{0}=1 \mathrm{~atm}$ in Eq. (3).

In practice, the mean temperature exponent will not be used to fit the 2S_KERO_BFER scheme parameters but the results for the dependence of

1 The pressure dependence of the two-step scheme will be assumed to be the one corresponding to a one-step scheme (Eq. (4)), a simple approximation which will be checked through the final calculation of flame speeds versus pressure in Section 4 . 
laminar flame speed with temperature presented in Section 4 will show that the temperature dependence is naturally preserved by the 2S_KERO_BFER scheme.

\section{Construction of the 2S_KERO_BFER scheme}

Section 2 has gathered all required data (laminar flame speeds, adiabatic temperatures and ignition delays) obtained from complex chemistry numerical simulations and experimental data. The present section describes how these data are used to calibrate the 2S_KERO_BFER scheme. Kerosene is replaced by an equivalent single species described in Section 3.1. Simplified transport and thermodynamic properties are derived for the kerosene-air mixture in Section 3.2. The kerosene oxidation reaction and the $\mathrm{CO}-\mathrm{CO}_{2}$ equilibrium are characterised in Section 3.3.

\subsection{Model for kerosene species}

In the 2S_KERO_BFER scheme, the kerosene species used is a model species of the fuel used by the three detailed or skeletal mechanisms and described in Table 1. It will be referred as KERO in the following. As detailed in Table 1, it is composed of ten atoms of carbon and twenty atoms of hydrogen. Its reference-state thermodynamic properties are obtained by a linear combination of the properties of $\mathrm{C}_{10} \mathrm{H}_{22}, \mathrm{C}_{9} \mathrm{H}_{12}$ and $\mathrm{C}_{9} \mathrm{H}_{18}$ species which are described by the NASA polynomial parametrization ${ }^{2}$ :

$\overline{2}$ The source for these polynomia is available on the NASA Glenn Research Center website (http://cea.grc.nasa.gov). 


$$
\begin{aligned}
& \frac{c_{p}^{\circ}}{R}(T)=a_{0}+a_{1} T+a_{2} T^{2}+a_{3} T^{3}+a_{4} T^{4}, \\
& \frac{h^{\circ}}{R}(T)=a_{0}+\frac{a_{1}}{2} T+\frac{a_{2}}{3} T^{2}+\frac{a_{3}}{4} T^{3}+\frac{a_{4}}{5} T^{4}+\frac{a_{5}}{T}, \\
& \frac{S^{\circ}}{R}(T)=a_{0} \ln (T)+a_{1} T+\frac{a_{2}}{2} T^{2}+\frac{a_{3}}{3} T^{3}+\frac{a_{4}}{4} T^{4}+a_{6},
\end{aligned}
$$

where the superscript $\circ$ denotes the reference state, $c_{p}^{\circ}$ is the specific heat capacity at constant pressure, $h^{\circ}$ is the enthalpy, $s^{\circ}$ is the entropy and the coefficients $a_{i}$ are given in Table 2 . This standard formulation is also used by CHEMKIN [27], COSILAB and CANTERA softwares.

\subsection{Transport and thermodynamic properties}

Using simple models for transport and thermodynamic properties is adequate when constructing a reduced chemical scheme [30]. A simple approach is to assume constant, but not necessarly equal, Lewis number for all species $L e_{k}=\lambda /\left(\rho c_{p} D_{k}\right)$ and a constant Prandtl number $\operatorname{Pr}=\mu c_{p} / \lambda=P r_{0}$, where $\rho$ is the gas mixture density, $c_{P}$ is the gas mixture specific heat capacity at constant pressure, $\lambda$ is the gas mixture thermal conductivity, $D_{k}$ is the diffusion coefficient for species $k$, and $\mu$ is the gas mixture dynamic viscosity following a power law:

$$
\mu(T)=\mu_{0}\left(\frac{T}{T_{0}}\right)^{\alpha}
$$

The Prandtl number $P r_{0}$ and the reference dynamic viscosity $\mu_{0}$, temperature $T_{0}$ and exponent $\alpha$ in Eq. (8) result from the detailed mechanism: $P r_{0}=0.739$ and $\mu_{0}=1.8456 \times 10^{-5} \mathrm{~kg} / \mathrm{m} / \mathrm{s}$. They correspond to the Prandtl number and 
dynamic viscosity in the burnt gases at the reference temperature $T_{0}=300 \mathrm{~K}$ whereas $\alpha=0.6695$ enables to fit the dependence on temperature over the whole range of temperature at atmospheric pressure [2].

In the perspective of a LES application of this chemical scheme, the unity Lewis number assumption for all species, $L e_{k}=1$, has been chosen in this work. This assumption is often imposed by the turbulent combustion models which assume equal turbulent diffusivities for all species. Both the laminar flame speed and flame structure may be affected by this assumption. The flame speed is usually understimated when assuming unity Lewis number in a detailed mechanism [2]. However when building a reduced mechanism, the laminar flame speed can be correctly predicted under the assumption of unity Lewis number for all species.

In mechanisms developed for light fuels like methane, the chemical structure in physical space (see Fig. 4a) is not greatly affected by the unity Lewis number assumption. Nevertheless, discrepancies appear by studying the flame structure in phase space, using a progress variable defined as $c=Y_{\mathrm{CO}}+Y_{\mathrm{CO} 2} / Y_{\mathrm{CO}}^{e q}+Y_{\mathrm{CO} 2}^{e q}$ (Fig. 4b) [15]. When working with heavy fuels like kerosene, the fuel profiles are more affected by the unity Lewis assumption (as shown in Figs. 5a and 5b) but it is still consistent with the other simplifications on simple models for molecular transport and thermodynamic data. 


\subsection{The semi-global chemical mechanism}

A reduced chemical mechanism must fulfill several conditions to be suitable for LES of turbulent combustion. First, the mechanism must describe correctly the equilibrium state so as to characterize the burnt gases. Then, the reduced scheme must be able to reproduce the experimental laminar flame speed (linked to the integrated fuel reaction rate) for a wide range of initial temperature, equivalence ratio and pressure. Moreover, a good description of the ignition delay is required. Finally, computational costs to introduce the reduced mechanism into a LES solver must be small.

The first question is to determine how many chemical species must be accounted for in the reduced scheme. Figure 6 compares the variations of adiabatic flame temperature with equivalence ratio obtained for a kerosene mixture composed of five species ( $F U E L, \mathrm{CO}_{2}, \mathrm{H}_{2} \mathrm{O}, \mathrm{N}_{2}, \mathrm{O}_{2}$ ), six species (FUEL, $\mathrm{CO}_{2}, \mathrm{H}_{2} \mathrm{O}, \mathrm{N}_{2}, \mathrm{O}_{2}+\mathrm{CO}$ ), seven species (FUEL, $\mathrm{CO}_{2}, \mathrm{H}_{2} \mathrm{O}, \mathrm{N}_{2}, \mathrm{O}_{2}+$ $\mathrm{CO}+\mathrm{H}_{2}$ ), and finally the 91 species accounted for in the LUCHE skeletal mechanism [40]. The fresh gas temperature is $T_{f}=473 \mathrm{~K}$ and the pressure is $P=1 \mathrm{~atm}$. For lean mixtures, five species (circles in Fig. 6) are sufficient to capture the equilibrium state. For rich mixtures however, the error increases up to $30 \%$ for $\phi=2.0$. When CO is included and six species (squares in Fig. 6) are taken into account, the error remains negligible for $\phi \leq 1.5$ and the maximum error is reduced to $11 \%$ for $\phi=2.0$ : taking into account $\mathrm{CO}$ greatly affects the equilibrium state for rich mixture and should be considered. This discrepancy for rich mixtures could even be reduced introducing $\mathrm{H}_{2}$ and using seven species (empty circles in Fig. 6). However adding $H_{2}$ increases 
the computational cost (one more equation has to be solved) and the system of conservation equations becomes numerically stiffer due to very different time scale reactions. For these reasons, only $\mathrm{CO}$ was added to the five initial species.

To add CO, a two-step scheme is required. Obviously, single-step mechanisms $[30,60]$ are easier to develop but the previous paragraph shows that the errors on temperature using five species only (and no $\mathrm{CO}$ ) are too large.

In the 2S_KERO_BFER scheme, the two reactions correspond to the fuel oxidation into $\mathrm{CO}$ and $\mathrm{H}_{2} \mathrm{O}$, followed by the $\mathrm{CO}$ oxidation into $\mathrm{CO}_{2}$. The second reaction is reversible and leads to the $\mathrm{CO}-\mathrm{CO}_{2}$ equilibrium in the burnt gases, required to reproduce the adiabatic flame temperature for rich flames, at least for $\phi<1.5$. Several approaches have been proposed to build two-step schemes: on the one hand, $\mathrm{Li}$ [61] and Sanchez [62] use the so-called slow CO oxidation limit of premixed combustion [63] which is valid for lean and stoichiometric mixture to derive a $C O$ oxidation reaction from detailed chemistry. Fuel oxidation in $\mathrm{H}_{2} \mathrm{O}$ and $\mathrm{CO}_{2}$ is described by two global reactions which take place in two different layers of the flame. First, fuel is attacked by radicals and totally oxidized in a thin layer called reaction zone, producing both $\mathrm{CO}$ and $\mathrm{H}_{2} \mathrm{O}$. Second, downstream from this thin layer, no fuel is left and radicals maintain a steady state, allowing a slow oxidation of $\mathrm{CO}$ into $\mathrm{CO}_{2}$ to take place in the so-called post-flame region which is thicker than the reaction zone. This approach provides an accurate description of the chemical flame structure for lean mixtures. However in aeronautical or piston engines, large local values of equivalence ratio can be found and the slow CO oxidation limit is too restrictive to be used in the context of LES in 
such configurations.

On the other hand, Westbrook \& Dryer [30] build a classical two-step mechanism by choosing the appropriate reaction parameters to fit flame speed measurements. This method has at least two disadvantages. First, it is more difficult to reproduce the flame structure for lean mixtures than it is using methods based on the $C O$ oxidation limit $[61,62]$. Second, it requires negative and/or small reaction exponents to correctly predict laminar flame speeds for rich mixtures. These exponents may lead to very unstable numerical implementation.

To correctly describe rich mixtures, one possibility would be to use a fourstep mechanism [31]. However for such complex mechanisms, it is difficult to determine the reaction parameters according to the one-step chemistry theory, which is all the more awkward when working on a wide range of pressure and temperature.

The 2S_KERO_BFER scheme is based on the two following reactions:

$$
\begin{gathered}
\mathrm{KERO}+10 \mathrm{O}_{2}=>10 \mathrm{CO}+10 \mathrm{H}_{2} \mathrm{O} \\
\mathrm{CO}+0.5 \mathrm{O}_{2}<=>\mathrm{CO}_{2}
\end{gathered}
$$

where the forward reaction rates for reactions (9) and (10) are written as:

$$
\begin{aligned}
& k_{f, 1}=A_{1} f_{1}(\phi) e^{\left(-E_{a, 1} / R T\right)}[\mathrm{KERO}]^{n_{\mathrm{KERO}}}\left[\mathrm{O}_{2}\right]^{n_{\mathrm{O}_{2}, 1}}, \\
& k_{f, 2}=A_{2} f_{2}(\phi) e^{\left(-E_{a, 2} / R T\right)}[\mathrm{CO}]^{n_{\mathrm{CO}}}\left[\mathrm{O}_{2}\right]^{n_{\mathrm{O}_{2}, 2},}
\end{aligned}
$$

where $A_{k}$ is the pre-exponential factor, $E_{a, k}$ is the activation energy of reaction $k$ and $n_{j, k}$ is the reaction exponent for species $j$ in reaction $k$. The subscripts 1 and 2 respectively denote the kerosene oxidation and the $\mathrm{CO}-\mathrm{CO}_{2}$ equi- 
librium reactions. The values for activation energy and reaction exponents are summarised in Table 4.

The reaction exponents $n_{j, k}$ have been chosen using Eq. (4) so that the obtained pressure exponent $\alpha_{P}$ is almost equal to the mean value of Table 3: $\alpha_{P}=-0.275$. Moreover, the activation energy $E_{a, 1}$ has been chosen to be close to the experimental values: $E_{a, 1}=4.15 \times 10^{4}$ and $E_{a}^{e x p}=4.09 \times 10^{4}$.

The first reaction controls the flame speed and the autoignition time. The second reaction which represents the $\mathrm{CO}-\mathrm{CO}_{2}$ equilibrium, is necessary to predict correctly the flame temperature and the $\mathrm{CO}$ levels in the burnt gases.

The solution used in the 2S_KERO_BFER scheme to adjust the rate coefficients is an extension of previous approaches where the rate constants are allowed to vary with equivalence ratio [36,44,45]. Reduced one- or two-step schemes guarantee proper flame predictions only for lean combustion and overestimate the laminar flame speed in the rich regime. Adjusting rate constants is an efficient method to circumvent this drawback: the first preexponential factor is tabulated versus equivalence ratio to reproduce the decrease in flame speed in the rich regime. Thus for rich flames, a correction function $f_{1}$ brings the flame speed to the LUCHE skeletal mechanism values. The correction function $f_{2}$ is calibrated to adjust the thickness of the post-flame zone and quickly reach the equilibrium state. The two correction functions $f_{1}$ and $f_{2}$ are displayed versus equivalence ratio in Fig. 7. For lean combustion, no correction is needed and both functions remain constant and equal to one. For rich combustion, the correction function $f_{2}$ decreases with equivalence ratio. Once $f_{2}$ is fixed, the correction function $f_{1}$ must be adjusted to match the flame speed. The two correction functions $f_{1}$ and $f_{2}$ 
do not depend on pressure or temperature. They are displayed in Fig. 7 and given by:

$$
\begin{aligned}
f_{1}(\phi) & =\frac{2}{\left.\left[1+\tanh \left(\frac{\phi_{0,1}-\phi}{\sigma_{0,1}}\right)\right]+B_{1}\left[1+\tanh \left(\frac{\phi-\phi_{1,1}}{\sigma_{1,1}}\right)\right]+C_{1}\left[1+\tanh \left(\frac{\phi-\phi_{2,1}}{\sigma_{2,1}}\right)\right]^{3}\right)} \\
f_{2}(\phi) & =\frac{1}{2}\left[1+\tanh \left(\frac{\phi_{0,2}-\phi}{\sigma_{0,2}}\right)\right]+\frac{B_{2}}{2}\left[1+\tanh \left(\frac{\phi-\phi_{1,2}}{\sigma_{1,2}}\right)\right] \\
& +\frac{C_{2}}{2}\left[1+\tanh \left(\frac{\phi-\phi_{2,2}}{\sigma_{2,2}}\right)\right] \times\left[1+\tanh \left(\frac{\phi_{3,2}-\phi}{\sigma_{3,2}}\right)\right]
\end{aligned}
$$

where the coefficients are summarised in Table 5 . Note that the correction function coefficients have been chosen to correctly describe the flame speed for a laminar premixed flame at fresh gas temperature $T_{f}=473 \mathrm{~K}$ and atmospheric pressure. Section 4 shows that this set of parameters allows an accurate prediction of flame speeds over a large range of equivalence ratio, pressure, temperature and dilution rate.

\section{Results}

To validate the behavior of the 2S_KERO_BFER, calculations of a premixed laminar flame have been performed for three different values of fresh gas temperature $\left(T_{f}=300,473,700 \mathrm{~K}\right)$ and pressure $(P=1,3,12 \mathrm{~atm})$. Fifteen equivalence ratios have been tested, from $\phi=0.6$ to $\phi=2.0$.

A comparison of the laminar flame speeds predicted by the 2S_KERO_BFER scheme, the DAGAUT detailed and the LUCHE skeletal mechanisms is displayed in Fig. 8. For the whole range of pressure and fresh gas temperature, the semi-global two-step mechanism predicts flame speeds which are close 
to the results of the two complex mechanisms. For lean and stoichiometric mixtures $(\phi<1.1)$, the reduced scheme is closer to the LUCHE skeletal mechanism, and to the experiments since the LUCHE skeletal mechanism shows better agreements with the experiments than the DAGAUT detailed mechanism in this region, as noticed in Section 2.1. The largest discrepancies are observed at stoichiometry, with a maximum error of $15 \%$ at atmospheric pressure. For rich mixtures, the 2S_KERO_BFER reduced scheme and the LUCHE skeletal mechanism are still in very good agreement. The discrepancies with the DAGAUT detailed mechanism are larger, with a maximum of $30 \%$ due to the differences observed between the two detailed mechanisms. However for rich flames, the measurements also show large uncertainties (30\%). Another interesting result concerns the reduced scheme pressure dependence for which two steps have been required. First, the fuel and oxidizer reaction exponents $n_{F}$ and $n_{O}$ have been fixed according to the mean pressure exponent $\bar{\alpha}_{P}$ given by the detailed mechanisms. Second, the coefficients of the correction functions $f_{1}$ and $f_{2}$ have been chosen to reproduce accurately the flame speed at atmospheric pressure and fresh gas temperature $T_{f}=473 \mathrm{~K}$. These two steps allow to provide an accurate pressure dependence of the flame speed for both lean and rich mixtures over the whole range of pressure. Moreover, the temperature dependence is naturally preserved.

The adiabatic temperature obtained with the 2S_KERO_BFER scheme has been compared to equilibrium values over the whole range of pressure, temperature and equivalence ratio. The agreement is very good, up to $\phi=1.5$, as expected from the results of Fig. 6 (Section 3.3). Figure 9 provides burnt gas temperature for the whole range of equivalence ratio at atmospheric 
pressure and initial temperature $T_{f}=473 \mathrm{~K}$, showing that adjusting the second reaction rate constant by the correction function $f_{2}$ allows to reduce the post-flame zone and to reach the equilibrium state quickly.

Furthermore regarding the ignition delay, the use of the experimental activation energy guarantees the correct prediction of the slope of the ignition delay time, as displayed in Fig. 10. The ignition delay time is plotted versus the inverse of fresh gas temperature for a stoichiometric flame at pressure $P=10 \mathrm{~atm}$ (Fig. 10a.) and $P=20 \mathrm{~atm}$ (Fig. 10b.). Comparisons with experiments [41-43] show that the ignition delay time is well predicted for a wide range of pressure using the $2 \mathrm{~S} \_$KERO_BFER scheme. It should be noticed that the ignition delay has been validated only for $900 K<T<1500 \mathrm{~K}$. A simplified mechanism is generally not able to correctly predict the autoignition for low temperature where chemical complexities are substantial. Nevertheless, the local ignition or extinction phenomena that occur in turbulent flames at high temperature are correctly described by the 2S_KERO_BFER mechanism.

Finally, the behavior of the 2S_KERO_BFER mechanism has been studied for two EGR dilution rates, $\tau_{E G R}=5 \%$ and $\tau_{E G R}=10 \%$ : the diluted fresh gases are composed of $\left(1-\tau_{E G R}\right)$ fresh gases and $\tau_{E G R}$ burnt gases in mass, both at fresh gas temperature. Figure 11 compares the semi-global two-step scheme with the LUCHE skeletal mechanism, showing that the flame speed of an EGR diluted flame at atmospheric conditions and initial temperature $T_{f}=473 \mathrm{~K}$ is correctly predicted. The discrepancies between the simplified mechanism and the skeletal one are negligible for $0.8 \leq \phi \leq 1.5$ (maximum error of $15 \%)$. Neglecting $\mathrm{H}_{2}$ and working with a two-step mechanism still lead to an overestimation of the burnt gas temperature for very rich di- 
luted flames $(\phi \geq 1.5)$. Nevertheless, Fig. 11b. shows that the decrease of the burnt gas temperature is correctly captured by the 2S_KERO_BFER scheme when dilution increases. As the construction of the two-step scheme does not account for any dilution effect, reproducing correct flame speeds and burnt gas temperatures for diluted flames is another natural capacity of the 2S_KERO_BFER scheme.

\section{Conclusion}

In the context of LES of reacting turbulent flows in industrial applications, a simplified mechanism has been preferred to tabulation methods for two reasons. First, they are easier to build for a wide range of pressure, temperature, equivalence ratio and EGR dilution rate, which is required in complex geometries where combustion may be fed by several streams with different temperatures and equivalence ratios for example. Second, the lookup table needed by tabulation methods in such situations is difficult to handle on massively parallel machines, leading to memory problems. Nevertheless in such applications, building a two-step mechanism valid for both lean and rich mixtures is difficult. Moreover, the pressure dependence of the flame speed must be carefully handled.

In the context of LES of reacting turbulent flows in industrial applications, the objective of this work was to build a reduced mechanism for kerosene-air premixed flames valid for a wide range of pressure, temperature, equivalence ratio and EGR dilution rate, which is required in complex geometries where combustion may be fed by several streams with different temperatures and equivalence ratios for example. 
The solution proposed in this work is to consider the two reactions of kerosene oxidation and $\mathrm{CO}-\mathrm{CO}_{2}$ equilibrium, and to tabulate the preexponential constants of these two reactions versus local equivalence ratio. Due to a lack of experimental results for kerosene-air combustion, the construction and validation of the 2S_KERO_BFER mechanism have been based on both the DAGAUT detailed mechanism which accounts for 209 species and 1673 reactions, and the LUCHE skeletal mechanism which accounts for 91 species and 991 reactions. The transport and thermodynamic properties have been simplified assuming unity Lewis numbers for all species and constant Prandtl number.

Computations of one-dimensional laminar flames have been performed with the 2S_KERO_BFER scheme for a wide range of pressure $(P \in[1 ; 12] \mathrm{atm})$, fresh gas temperature $\left(T_{f} \in[300 ; 700] K\right)$, equivalence ratio $(\phi \in[0.6 ; 2.0])$ and EGR dilution rate $\left(\tau_{E G R} \in[0 ; 10] \%\right)$. Comparisons with the LUCHE skeletal mechanism show that:

- the flame speed is correctly predicted by the reduced scheme for the whole range of parameters, showing a maximum for stoichiometric flames and a decrease for rich combustion. Due to the choice of the fuel and oxidizer exponents, the pressure dependence is well reproduced whereas the temperature dependence is naturally preserved;

- the burnt gas temperature is well predicted, although showing discrepancies for very rich flames which would require to account for $\mathrm{H}_{2}$ species, increasing the number of reactions to consider;

- the dilution by EGR shows a decrease in flame speed and burnt gas temperature, as predicted by the detailed mechanism. Still, neglecting $\mathrm{H}_{2}$ affects the results on burnt gas temperature for very rich mixtures 
$(\phi>1.5)$

- the ignition delay time is in good agreement with the experiments for a wide range of pressure.

Following Westbrook \& Dryer [30] who showed that the simplified rate expression parameters do not change strongly with fuel molecule size, the methodology proposed in this work to construct a semi-global two-step mechanism over a wide range of operating parameters could be used for other hydrocarbons. Even the fuel and oxidizer reaction exponents as well as the two correction functions fitted for kerosene could be roughly used for very similar fuels such as n-decane for instance. However for very small molecules such as methane, the methodology should be modified, mainly because the pressure exponent is not constant for the whole range of pressure targeted in this work.

The next objective consists in evaluating the performances of the 2S_KERO_BFER scheme in LES of turbulent reactive flows, varying the operating points.

\section{Acknowledgement}

This research project has been supported by a Marie Curie Early Stage Research Training Fellowship of the European Communitys Sixth Framework Programme under contract number MEST-CT-2005-020426. 


\section{References}

[1] N. Peters, Turbulent combustion, Cambridge University Press, 2001.

[2] T. Poinsot, D. Veynante, Theoretical and Numerical Combustion, R.T. Edwards, 2nd edition., 2005.

[3] S. B. Pope, Prog. Energy Comb. Sci. 19 (11) (1985) 119-192.

[4] U. Maas, S. B. Pope, Combust. Flame 88 (1992) 239-264.

[5] S. B. Pope, Combust. Theory and Modelling 1 (1997) 41-63.

[6] M. A. Singer, S. B. Pope, Combust. Theory and Modelling 8 (2) (2004) 361 383.

[7] R. W. Bilger, Phys. Fluids A 5 (22) (1993) 436-444.

[8] A. Y. Klimenko, R. W. Bilger, Prog. Energy Comb. Sci. 25 (6) (1999) 595 - 687.

[9] S. H. Kim, H. Pitsch, Phys. Fluids 17 (10) (2005) 105103.1-105103.12.

[10] S. Navarro-Martinez, A. Kronenburg, Proc. Combust. Inst. 31 (2007) 1721-1728.

[11] J. A. van Oijen, F. A. Lammers, L. P. H. de Goey, Combust. Sci. Tech. 127 (2001) 2124-2134.

[12] L. P. H. de Goey, J. A. van Oijen, H. Bongers, G. R. A. Groot, New flamelet based reduction methods: the bridge between chemical reduction techniques and flamelet methods, in: European Combustion Meeting, Orléans (France), 2003.

[13] O. Gicquel, N. Darabiha, D. Thévenin, Proc. Combust. Inst. 28 (2000) 19011908.

[14] B. Fiorina, R. Baron, O. Gicquel, D. Thévenin, S. Carpentier, N. Darabiha, Combust. Theory and Modelling 7 (2003) 449-470. 
[15] B. Fiorina, O. Gicquel, L. Vervisch, S. Carpentier, N. Darabiha, Proc. Combust. Inst. 30 (1) (2005) 867-874.

[16] J. Galpin, C. Angelberger, A. Naudin, L. Vervisch, J. Turb. 9 (13).

[17] J. Michel, O. Colin, D. Veynante, Combust. Flame 152 (2008) 80-99.

[18] R. S. Barlow, Proc. Combust. Inst. 31 (2006) 49-75.

[19] H. Pitsch, H. Steiner, Phys. Fluids 12 (2000) 2541-2554.

[20] O. Stein, A. Kempf, Proc. Combust. Inst. 31 (2007) 1755-1763.

[21] A. Kempf, Flow, Turb. and Combustion 80 (2008) 351-373.

[22] B. Böhm, J. Brübach, C. Ertem, A. Dreizler, Flow, Turb. and Combustion 80 (4) (2007) 507-529.

[23] J. Riley, J. Fluids Eng. 128 (2) (2006) 209-215.

[24] G. Ribert, O. Gicquel, N. Darabiha, D. Veynante, Combust. Flame 146 (2006) $649-664$

[25] D. Veynante, B. Fiorina, P. Domingo, L. Vervisch, Combust. Theory and Modelling 12 (6) (2008) 1055-1088.

[26] B. Fiorina, O. Gicquel, D. Veynante, Proc. Comb. Institute 32 (2009) 1687-1694.

[27] R. J. Kee, F. Rupley, E. Meeks, Sandia National Laboratories, SAND96-8216 (1996).

[28] R. Cabra, J.-Y. Chen, R. Dibblea, A. Karpetis, R. Barlow, Combust. Flame 143 (2005) 491-506.

[29] P. Domingo, L. Vervisch, D. Veynante, Combust. Flame 152 (2007) 415-432.

[30] C. Westbrook, F. Dryer, Combust. Sci. Tech. 27 (1981) 31-43.

[31] W. P. Jones, R. P. Lindstedt, Combust. Flame 73 (1988) 222-233. 
[32] J. Galpin, A. Naudin, L. Vervisch, C. Angelberger, O. Colin, P. Domingo, Combust. Flame 155 (1-2) (2008) 247-266.

[33] F. di Mare, W. P. Jones, K. Menzies, Combust. Flame 137 (2004) 278-295.

[34] P. Schmitt, T. J. Poinsot, B. Schuermans, K. Geigle, J. Fluid Mech. 570 (2007) $17-46$.

[35] M. Boileau, G. Staffelbach, B. Cuenot, T. Poinsot, C. Bérat, Combust. Flame $154(1-2)(2008) 2-22$.

[36] G. Boudier, L. Y. M. Gicquel, T. Poinsot, D. Bissières, C. Bérat, Combust. Flame 155 (1-2) (2008) 196-214.

[37] N. Patel, S. Menon, Combust. Flame 153 (1-2) (2008) 228-257.

[38] A. Triantafyllidis, E. Mastorakos, R. Eggels, Combust. Flame 156 (2009) 23282345.

[39] H. Eberius, P. Frank, T. Kick, C. Naumann, U. Steil, C.Wahl, Final report for subtask 1.2.3 (D 1.7) (2001).

[40] J. Luche, Elaboration of reduced kinetic models of combustion. Application to a kerosene mechanism, Ph.D. thesis, LCSR Orléans (2003).

[41] P. Dagaut, M. Cathonnet, Prog. Energy Comb. Sci. 32 (2006) 48-92.

[42] S. Vasu, D. Davidsona, R. Hanson, Combust. Flame 152 (2007) 125-143.

[43] A. Dean, O. Penyazkov, K. Sevruk, B. Varatharajan, Proc. Combust. Inst. 31 (2007) 2481-2488.

[44] J.-P. Légier, Simulations numériques des instabilités de combustion dans les foyers aéronautiques, Phd thesis, INP Toulouse (2001).

[45] E. Fernandez-Tarrazo, A. Sanchez, A. Linan, F. Williams, Combust. Flame 147 (1-2) (2006) 32-38. 
[46] D.G.Goodwin, Cantera C++ Users Guide, http://sourceforge.net/pro jects/cantera (2002).

[47] COSILAB, The Combustion Simulation Laboratory, Version 3.0, www.SoftPredict.com, Rotexo GmbH \& Co. KG, Haan (Germany) (2009).

[48] D. R. Dowdy, D. B. Smith, S. C. Taylor, A. Williams, Proc. Combust. Inst. 23 (1991) 325-332.

[49] K. T. Aung, M. I. Hassan, G. M. Faeth, Combust. Flame 109 (1997) 1-24.

[50] D. Bradley, M. Lawes, K. Liu, S. Verhelst, R. Woolley, Combust. Flame 149 (2007) 162-172.

[51] F. N. Egolfopoulos, P. Cho, C. K. Law, Combust. Flame 76 (1989) 375-391.

[52] M. I. Hassan, K. T. Aung, G. M. Faeth, Combust. Flame 115 (4) (1998) 539-550.

[53] X. J. Gu, M. Z. Haq, M. Lawes, R. Woolley, Combust. Flame 121 (2000) 41-58.

[54] A. Mestre, F. Ducourneau, Recent studies of the spontaneous ignition of rich air-kerosine mixtures, in: F. Weinberg (Ed.), Combust. Inst. European Symp. , Academic Press, London, 1973, pp. 225-229.

[55] L. Spadaccini, J. Tevelde, Combust. Flame 46 (1981) 283-300.

[56] G. Freeman, A. Lefebvre, Combust. Flame 58 (1984) 153-162.

[57] J. Luche, M. Reuillon, J.-C. Boettner, M. Cathonnet, Combust. Sci. Tech. 176 (2004) 1935-1963.

[58] T.F.Lu, C.K.Law, Proc. Comb. Institute 30 (2005) 1333-1341.

[59] M. Metghalchi, J. C. Keck, Combust. Flame 38 (1980) 143-154.

[60] S. Aly, H. Salem, Fuel 68 (1989) 1203-1209.

[61] S. Li, F. Williams, K. Gebert, Combust. Flame 119 (1999) 367-373. 
[62] A. Sánchez, A. Lépinette, M. Bollig, A. Linán, B. Lázaro, Combust. Flame 123 (2000) 436-464.

[63] M. Bui-Pham, K. Seshadri, F. Williams, Combust. Flame 89 (1992) 343-362. 


\section{List of Tables}

1 Composition of KERO species in [40].

2 Coefficients of the NASA polynoms for kerosene for two ranges of temperature: [300;1000] K and [1000;5000] K. The source for these polynomia is available on the NASA Glenn Research Center website (http://cea.grc.nasa.gov).

3 Pressure exponent $\alpha_{P}$ at $T_{f}=300 \mathrm{~K}$, and temperature exponent $\alpha_{T}$ at $P=1 \mathrm{~atm}$ obtained from the LUCHE skeletal mechanism for three equivalence ratios: $\phi=0.8,1.0,1.2$.

4 Activation energy $E_{a}$, pre-exponential factor $A$, and reaction exponents $n_{k}$ used for the 2S_KERO_BFER mechanism. Units are: $\mathrm{mol}, \mathrm{s}, \mathrm{cm}^{3}$, J and $\mathrm{cal} / \mathrm{mol}$.

5 Coefficients for the two correction functions in the 2S_KERO_BFER scheme. 


\section{Tables}

\begin{tabular}{|c|c|c|c|c|}
\hline & Composition & Mass Fraction & Molar Weight & Molar Fraction \\
{$[-]$} & {$[\mathrm{g} / \mathrm{mol}]$} & {$[-]$} \\
\hline \hline Linear & $\mathrm{C}_{10} \mathrm{H}_{22}$ & 0.767 & 142.284 & 0.7396 \\
\hline Aromatic & $\mathrm{C}_{9} \mathrm{H}_{12}$ & 0.132 & 120.1916 & 0.1507 \\
\hline Naphthenic & $\mathrm{C}_{9} \mathrm{H}_{18}$ & 0.101 & 126.241 & 0.1097 \\
\hline \hline KERO & $C_{9.7396} \mathrm{H}_{20.0542}$ & 1.000 & 137.195 & 1.000 \\
\hline
\end{tabular}

Table 1

Composition of KERO species in [40]. 


\begin{tabular}{|c||c|c|}
\hline Coefficients & $T \in[300 ; 1000] K$ & $T \in[1000 ; 5000] K$ \\
\hline \hline$a_{0}$ & -4.15 & 22.0 \\
$a_{1}$ & $1.28 \times 10^{-1}$ & $5.61 \times 10^{-2}$ \\
$a_{2}$ & $-1.08 \times 10^{-4}$ & $-2.09 \times 10^{-5}$ \\
$a_{3}$ & $6.53 \times 10^{-8}$ & $3.57 \times 10^{-9}$ \\
$a_{4}$ & $-2.08 \times 10^{-11}$ & $-2.30 \times 10^{-13}$ \\
$a_{5}$ & $-2.83 \times 10^{+04}$ & $-3.61 \times 10^{+04}$ \\
$a_{6}$ & $5.09 \times 10^{+1}$ & $8.60 \times 10^{+1}$ \\
\hline
\end{tabular}

Table 2

Coefficients of the NASA polynoms for kerosene for two ranges of temperature: [300;1000] K and [1000;5000] K. The source for these polynomia is available on the NASA Glenn Research Center website (http://cea.grc.nasa.gov). 
Table 3

\begin{tabular}{|c|c|c|c|c|}
\hline & \multicolumn{2}{|c|}{ LUCHE } & \multicolumn{2}{c|}{ DAGAUT } \\
\hline$\phi[-]$ & $\alpha_{P}[-]$ & $\alpha_{T}[-]$ & $\alpha_{P}[-]$ & $\alpha_{T}[-]$ \\
\hline \hline 0.8 & -0.250 & 1.932 & -0.311 & 1.949 \\
1.0 & -0.312 & 1.775 & -0.271 & 1.812 \\
1.2 & -0.300 & 1.789 & -0.332 & 1.849 \\
\hline
\end{tabular}

Pressure exponent $\alpha_{P}$ at $T_{f}=300 \mathrm{~K}$, and temperature exponent $\alpha_{T}$ at $P=1 \mathrm{~atm}$ obtained from the LUCHE skeletal mechanism for three equivalence ratios: $\phi=$ $0.8,1.0,1.2$. 


\begin{tabular}{|c|c|c|c|c|}
\hline & \multicolumn{2}{|c|}{ KERO oxidation } & \multicolumn{1}{c|}{$C O-\mathrm{CO}_{2}$ equilibrium } \\
\hline \hline Activation energy & \multicolumn{2}{|c|}{$4.15 \times 10^{4}$} & \multicolumn{2}{|c|}{$2.0 \times 10^{4}$} \\
\hline Pre-exponential factor & \multicolumn{2}{|c|}{$8.00 \times 10^{11}$} & \multicolumn{2}{|c|}{$4.5 \times 10^{10}$} \\
\hline Reaction & $n_{K E R O}$ & 0.55 & $n_{\mathrm{CO}}$ & 1.00 \\
exponents (-) & $n_{\mathrm{O}_{2}, 1}$ & 0.90 & $n_{\mathrm{O}_{2,2}}$ & 0.50 \\
\hline
\end{tabular}

Table 4

Activation energy $E_{a}$, pre-exponential factor $A$, and reaction exponents $n_{k}$ used for the 2S_KERO_BFER mechanism. Units are: $\mathrm{mol}, \mathrm{s}, \mathrm{cm}^{3}$, J and cal $/ \mathrm{mol}$. 


\begin{tabular}{|c|c|c|c|c|c|c|c|c|c|c|}
\hline & $\phi_{0, j}$ & $\sigma_{0, j}$ & $B_{j}$ & $\phi_{1, j}$ & $\sigma_{1, j}$ & $C_{j}$ & $\phi_{2, j}$ & $\sigma_{2, j}$ & $\phi_{3, j}$ & $\sigma_{3, j}$ \\
\hline \hline$j=1$ & 1.173 & 0.04 & 0.29 & 1.2 & 0.02 & 7.1 & 1.8 & 0.18 & - & - \\
\hline$j=2$ & 1.146 & 0.045 & 0.00015 & 1.2 & 0.04 & 0.035 & 1.215 & 0.03 & 1.32 & 0.09 \\
\hline
\end{tabular}

Table 5

Coefficients for the two correction functions in the 2S_KERO_BFER scheme. 


\section{List of Figures}

1 a) Ignition delay versus inverse of fresh gas temperature: experimental data provided in [41-43] $(\times)$ and results of Eq. (1) (-); b) Laminar flame speed versus equivalence ratio at $P=1 \mathrm{~atm}$ and fresh gas temperature $T_{f}=473 \mathrm{~K}$ for kerosene $(\Delta)$, n-decane $(O)$ and a mixture of n-decane/n-probylbenzene $(\times)$ [39].

2 Flame speed versus equivalence ratio at fresh gas temperature $T_{f}=473 \mathrm{~K}$ and pressure $P=1 \mathrm{~atm}$. Comparison between the DAGAUT detailed mechanism [41] (--- -), the EL-BAKALI_RISTORI detailed mechanism [57] (-), the LUCHE skeletal mechanism [40] (- -), and the experimental results $[39](\Delta)$.

3 Flame speed versus pressure at $T=473 K$ (a.) and versus temperature at $P=1 \mathrm{~atm}$ (b.). Comparison between LUCHE skeletal mechanism results (see Table 3) and Eq. (3) using $P_{0}=1 \mathrm{~atm}, \alpha_{P}=\bar{\alpha}_{P}=-0.275, T_{0}=473 \mathrm{~K} \mathrm{~T}_{0}=300 \mathrm{~K}$ and $\alpha_{T}=\bar{\alpha}_{T}=1.9$, for three equivalence ratios: $\phi=0.8(\mathrm{LUCHE}$ skeletal mechanism: $\mathbf{\square}$ and Eq. (3): - - ), 1.0 ( $\boldsymbol{\nabla}$ and ---) $1.2(\bigcirc$ and -). 
4 Species profiles for a methane-air flame using the GRI-MECH detailed scheme [?] in physical space (detail of the reaction zone, a.) and phase space (b.), for $\phi=1.0, T_{f}=473 \mathrm{~K}$ and $P=1 \mathrm{~atm} . \mathrm{CH}_{4}$ with detailed $(\triangle)$ and simplified transport $(--), C O$ with detailed $(O)$ and simplified $(-)$ transport, $\mathrm{CO}_{2}$ with detailed $(\times)$ and simplified (---) transport properties.

5 Species profiles for a kerosene-air flame using the LUCHE skeletal scheme [40] in physical space (detail of the reaction zone, a.) and phase space (b.), for $\phi=1.0, T=473 \mathrm{~K}$ and $P=1$ atm. KERO with detailed $(\triangle)$ and simplified transport (- -), $\mathrm{CO}$ with detailed $(\mathrm{O})$ and simplified $(-)$ transport, $\mathrm{CO}_{2}$ with detailed $(\times)$ and simplified (---) transport properties.

6 Adiabatic temperature versus equivalence ratio at fresh gas temperature $T_{f}=473 \mathrm{~K}$ and pressure $P=1 \mathrm{~atm}$. Comparison between the LUCHE skeletal mechanism [40] (-) and simplified mixtures composed of $5(\bullet), 6(\boldsymbol{\square})$ and 7 (॰) species (Equilibrium computations with CANTERA).

7 Evolution of the correction functions $f_{1}(-)$ and $f_{2}(-\cdot-)$ versus equivalence ratio. 
8 Laminar flame speed versus equivalence ratio at fresh gas temperature $T_{f}=300 \mathrm{~K}\left(\mathrm{a}\right.$.), $T_{f}=473 \mathrm{~K}\left(\mathrm{~b}\right.$.) and $T_{f}=700 \mathrm{~K}$ (c.). Comparison between 2S_KERO_BFER scheme (-, - $-,--)$, LUCHE skeletal mechanism $(\bullet, \mathbf{0}, \mathbf{\Delta})$ and DAGAUT detailed mechanism $(\diamond, O, \Delta)$ for pressure $P=1,3,12 \mathrm{~atm}$ respectively.

9 Burnt gas temperature versus equivalence ratio. Comparison between LUCHE skeletal mechanism (-), equilibrium results $(\times)$ and 2S_KERO_BFER scheme $(\mathbf{O})$ scheme at pressure $P=1 \mathrm{~atm}$ and fresh gas temperature $T_{f}=473 \mathrm{~K}$.

10 Ignition delay versus inverse of fresh gas temperature for a stoichiometric flame at pressure $P=10 \mathrm{~atm}$ (a.) and $P=20 \mathrm{~atm}$ (b.). Comparison between experimental data [41] (\# and $\times$ respectively) and 2 S_KERO_BFER scheme predictions ( $\mathbf{\square}$ and $\mathbf{O}$ ).

11 Flame speed (a.) and burnt gas temperature (b.) at pressure $P=1 \mathrm{~atm}$ and fresh gas temperature $T_{f}=473 \mathrm{~K}$. Comparison between 2S_KERO_BFER scheme and LUCHE skeletal mechanism without EGR dilution (— and $\bullet$ respectively), with $5 \%$ EGR dilution (-- and respectively), and with $10 \%$ EGR dilution (- - and $\boldsymbol{\Delta}$ respectively). 


\section{Figures}
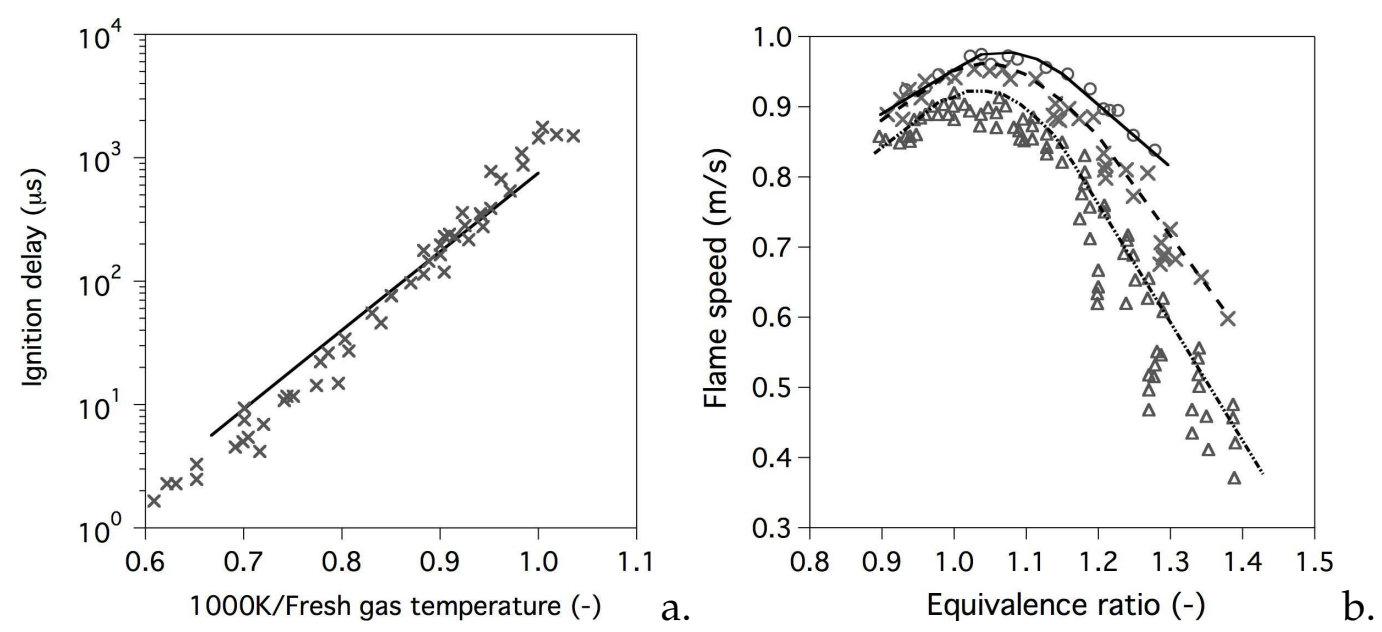

Fig. 1. a) Ignition delay versus inverse of fresh gas temperature: experimental data provided in [41-43] $(\times)$ and results of Eq. (1) (-); b) Laminar flame speed versus equivalence ratio at $P=1 \mathrm{~atm}$ and fresh gas temperature $T_{f}=473 \mathrm{~K}$ for kerosene $(\triangle)$, n-decane $(\bigcirc)$ and a mixture of n-decane/n-probylbenzene $(\times)$ [39]. 


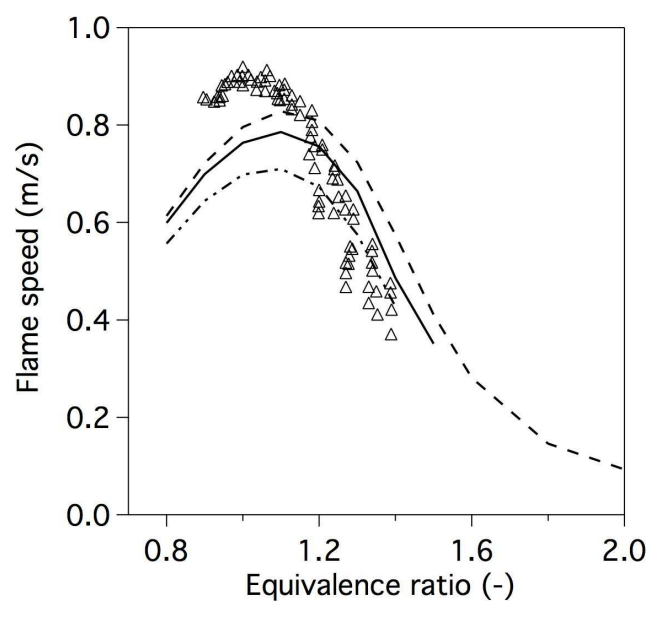

Fig. 2. Flame speed versus equivalence ratio at fresh gas temperature $T_{f}=473 \mathrm{~K}$ and pressure $P=1 \mathrm{~atm}$. Comparison between the DAGAUT detailed mechanism [41] (-- -), the EL-BAKALI_RISTORI detailed mechanism [57] (-), the LUCHE skeletal mechanism [40] (- -), and the experimental results [39] $(\Delta)$. 

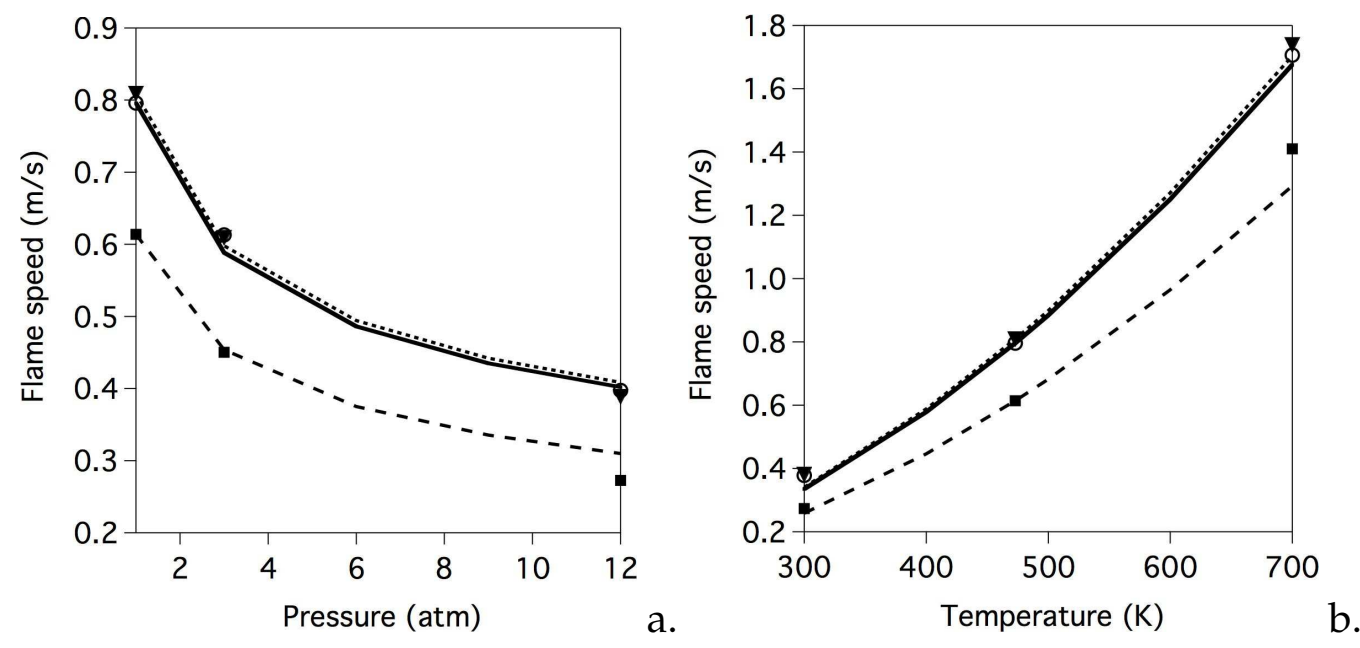

Fig. 3. Flame speed versus pressure at $T=473 K$ (a.) and versus temperature at $P=1 \mathrm{~atm}$ (b.). Comparison between LUCHE skeletal mechanism results (see Table 3) and Eq. (3) using $P_{0}=1 \mathrm{~atm}, \alpha_{P}=\bar{\alpha}_{P}=-0.275, T_{0}=473 \mathrm{~K} T_{0}=300 \mathrm{~K}$ and $\alpha_{T}=\bar{\alpha}_{T}=1.9$, for three equivalence ratios: $\phi=0.8$ (LUCHE skeletal mechanism: and Eq. (3): - - ), 1.0 ( $\boldsymbol{\nabla}$ and ---) $1.2(\mathrm{O}$ and -$)$. 

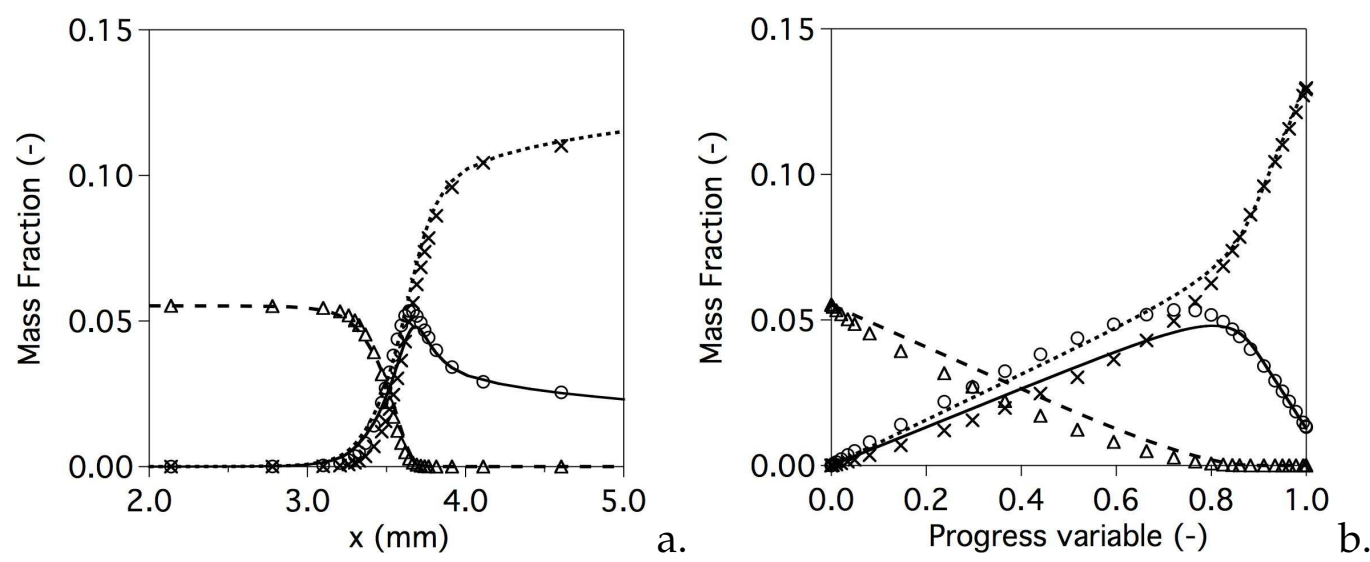

Fig. 4. Species profiles for a methane-air flame using the GRI-MECH detailed scheme [?] in physical space (detail of the reaction zone, a.) and phase space (b.), for $\phi=1.0, T_{f}=473 \mathrm{~K}$ and $P=1 \mathrm{~atm} . \mathrm{CH}_{4}$ with detailed $(\triangle)$ and simplified transport $(--), \mathrm{CO}$ with detailed $(\mathrm{O})$ and simplified (-) transport, $\mathrm{CO}_{2}$ with detailed $(\times)$ and simplified (--) transport properties. 

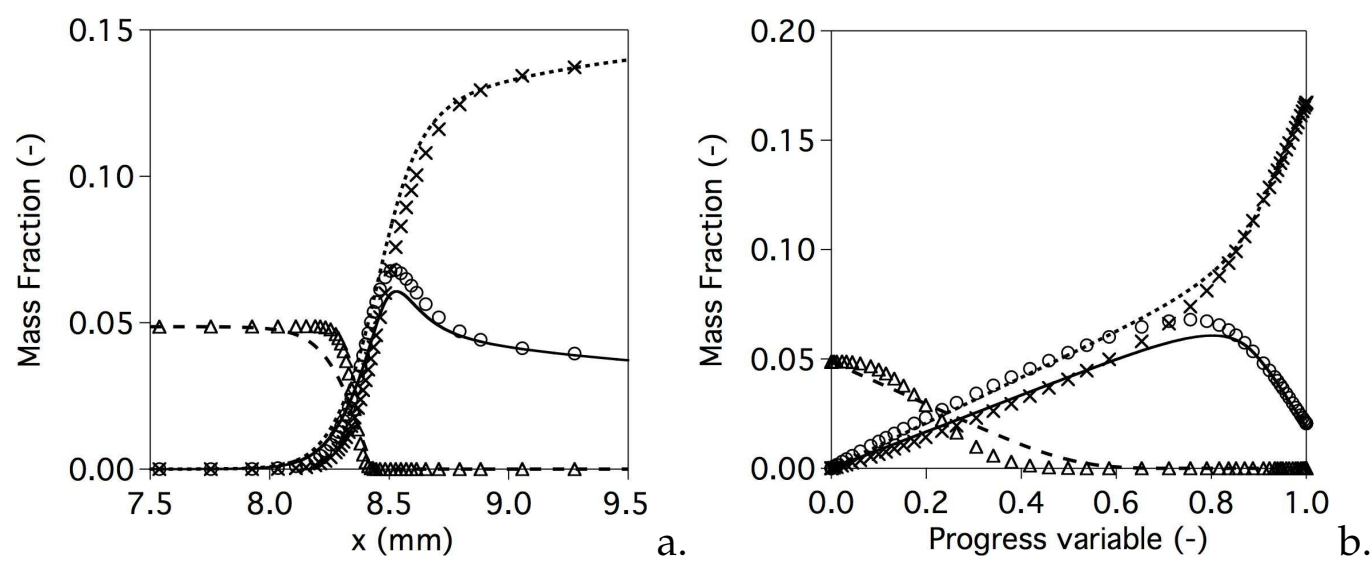

Fig. 5. Species profiles for a kerosene-air flame using the LUCHE skeletal scheme [40] in physical space (detail of the reaction zone, a.) and phase space (b.), for $\phi=1.0, T=473 \mathrm{~K}$ and $P=1 \mathrm{~atm} . K E R O$ with detailed $(\triangle)$ and simplified transport (- -), $\mathrm{CO}$ with detailed $(\mathrm{O})$ and simplified (-) transport, $\mathrm{CO}_{2}$ with detailed $(\times)$ and simplified (---) transport properties. 


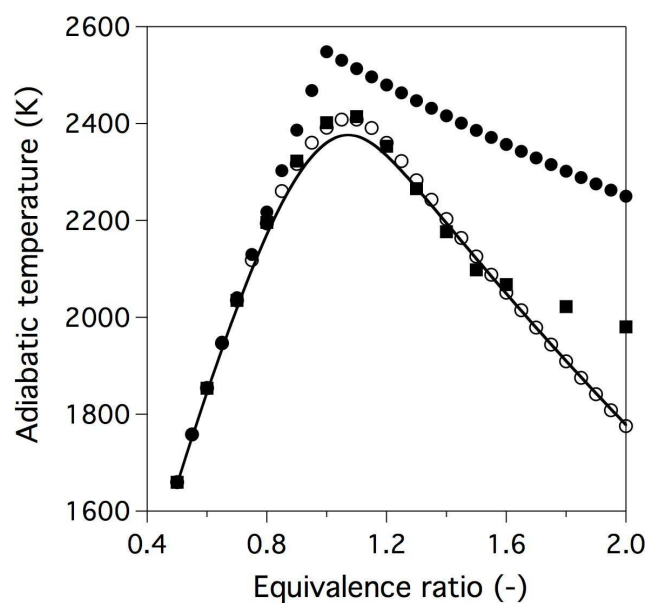

Fig. 6. Adiabatic temperature versus equivalence ratio at fresh gas temperature $T_{f}=473 \mathrm{~K}$ and pressure $P=1 \mathrm{~atm}$. Comparison between the LUCHE skeletal mechanism [40] (一) and simplified mixtures composed of $5(\bullet), 6(\mathbf{\square})$ and 7 (०) species (Equilibrium computations with CANTERA). 


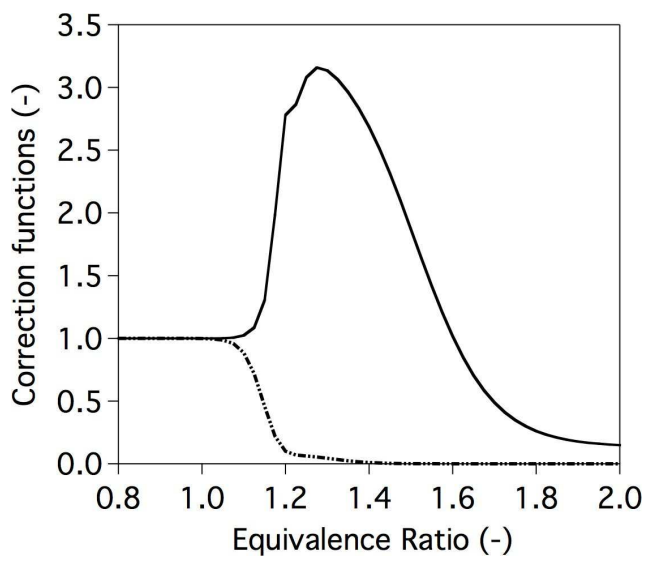

Fig. 7. Evolution of the correction functions $f_{1}(-)$ and $f_{2}(-\cdot-)$ versus equivalence ratio. 

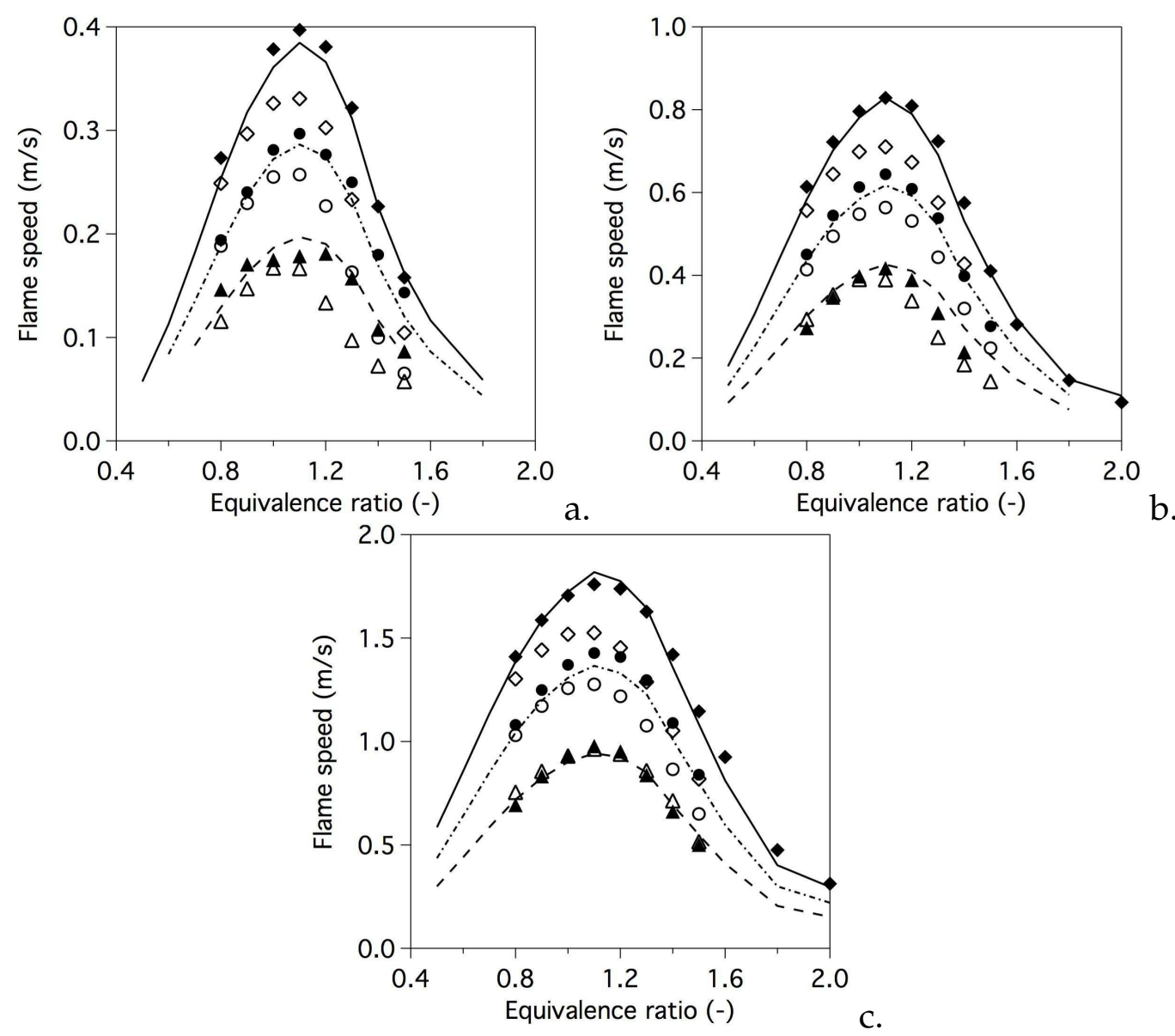

Fig. 8. Laminar flame speed versus equivalence ratio at fresh gas temperature $T_{f}=300 \mathrm{~K}$ (a.), $T_{f}=473 \mathrm{~K}$ (b.) and $T_{f}=700 \mathrm{~K}$ (c.). Comparison between 2S_KERO_BFER scheme (-, - -,$-\boldsymbol{-})$, LUCHE skeletal mechanism $(\bullet, \bullet, \mathbf{\Delta})$ and DAGAUT detailed mechanism $(\diamond, \bigcirc, \Delta)$ for pressure $P=1,3,12 \mathrm{~atm}$ respectively. 


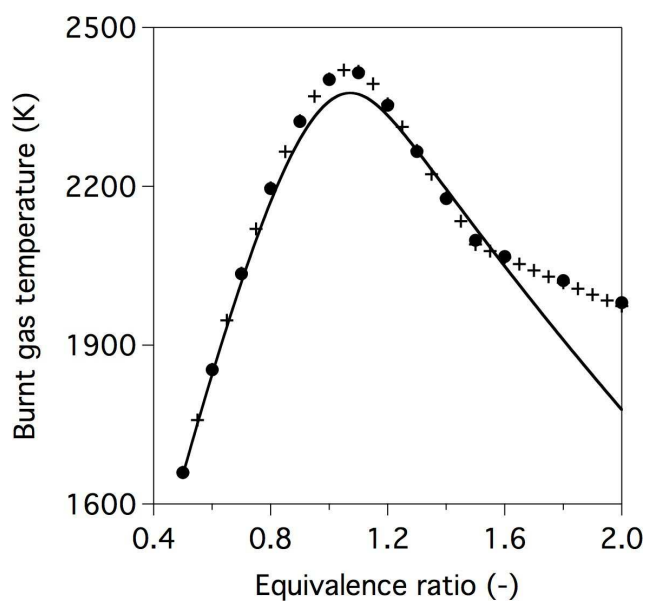

Fig. 9. Burnt gas temperature versus equivalence ratio. Comparison between LUCHE skeletal mechanism (-), equilibrium results $(\times)$ and 2S_KERO_BFER scheme $(\mathbf{O})$ scheme at pressure $P=1 \mathrm{~atm}$ and fresh gas temperature $T_{f}=473 \mathrm{~K}$. 

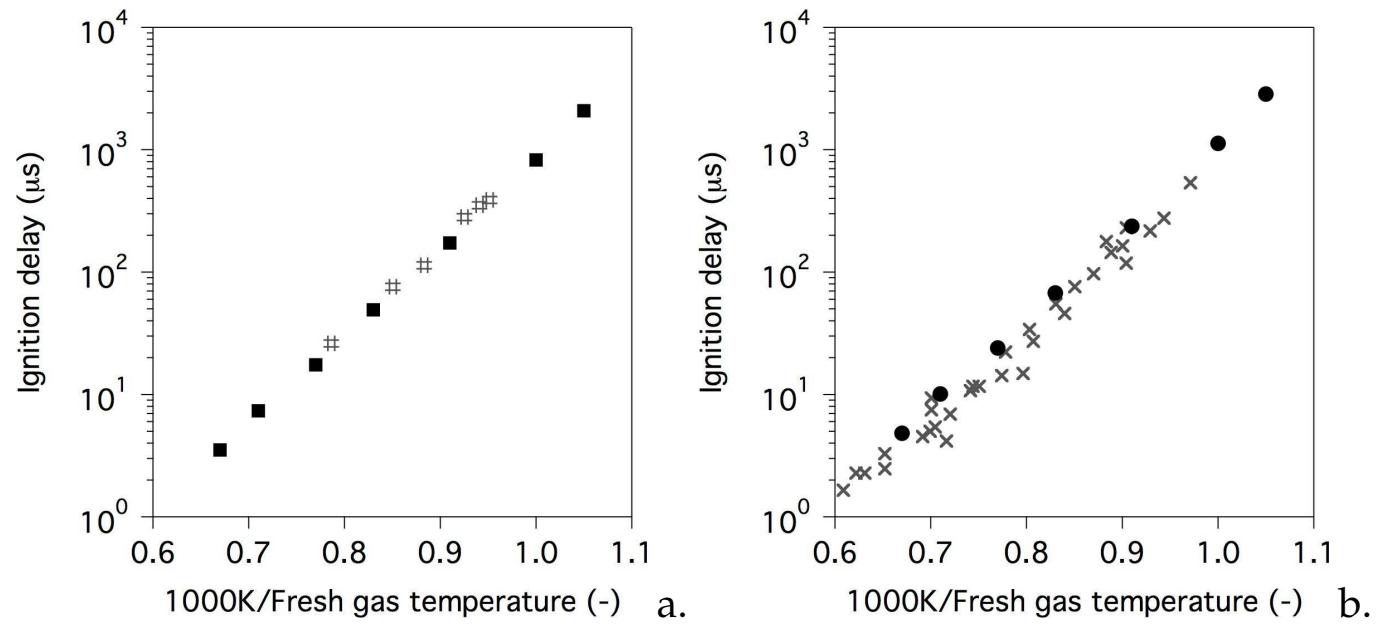

Fig. 10. Ignition delay versus inverse of fresh gas temperature for a stoichiometric flame at pressure $P=10 \mathrm{~atm}$ (a.) and $P=20 \mathrm{~atm}$ (b.). Comparison between experimental data [41] (\# and $\times$ respectively) and 2S_KERO_BFER scheme predictions ( and $\mathbf{0}$. 

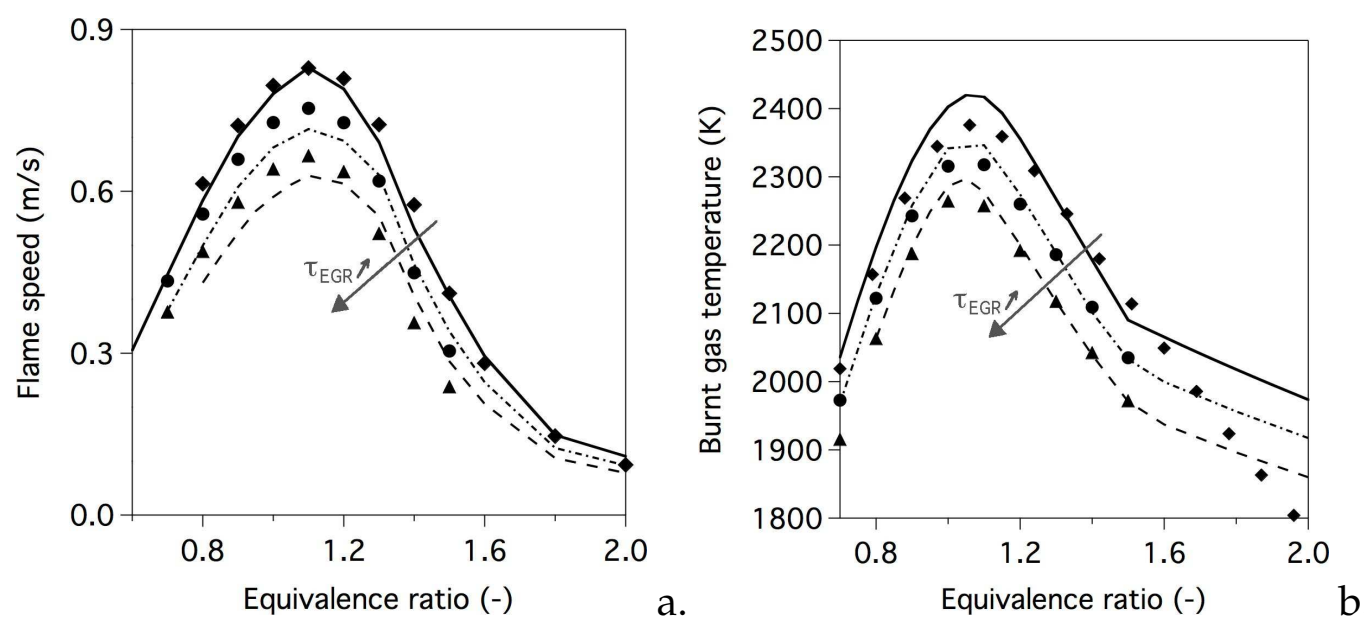

Fig. 11. Flame speed (a.) and burnt gas temperature (b.) at pressure $P=1 \mathrm{~atm}$ and fresh gas temperature $T_{f}=473 \mathrm{~K}$. Comparison between 2S_KERO_BFER scheme and LUCHE skeletal mechanism without EGR dilution (— and $\bullet$ respectively), with $5 \%$ EGR dilution (- - and respectively), and with $10 \%$ EGR dilution (- and $\boldsymbol{\Delta}$ respectively). 